\title{
PERTEKMA Financial Reporting Tool
}

\author{
TEE LEE MAY \& MOHAMAD JOHAN AHMAD KHIRI*
}

\author{
Faculty of Computer Science and Information Technology, Universiti Malaysia Sarawak, 94300 Kota \\ Samarahan, Sarawak, Malaysia \\ *Corresponding authors: 58116@siswa.unimas.my; akmjohan@unimas.my
}

\begin{abstract}
A financial management system is essential for any organization to manage its cash flow and keep track of its spending and earnings. Currently, our faculty-student organization, Persatuan Teknologi Maklumat (PERTEKMA), still uses multiple Excel spreadsheets to log in financial records and depend on physical ledgers printed from the Excel sheet to keep track of its accounts. This project aims to develop a web-based system that keeps track of the PERTEKMA association's revenue and spending and prevents inconsistencies between different ledgers such as activity and kiosk ledgers maintained by various executive committees (Exco) members of PERTEKMA. The system's targeted users are PERTEKMA Exco members and the lecturers responsible for supervising PERTEKMA. The methodology used to develop the proposed project is the Rapid Application Development (RAD) model. An interview was carried out with two treasurers in PERTEKMA to obtain the requirements, and their suggestions were used to develop and design the proposed system. In addition, an interview session was carried out with two PERTEKMA advisors to collect the system requirements to design the system. The system developed aims to replace the current approach to managing financial records through a centralized online platform.
\end{abstract}

Keywords: PERTEKMA, Financial report, Web-based system

Copyright: This is an open-access article distributed under the terms of the CC-BY-NC-SA (Creative Commons Attribution-NonCommercial-ShareAlike 4.0 International License) which permits unrestricted use, distribution, and reproduction in any medium, for non-commercial purposes, provided the original work of the author(s) is properly cited.

\section{INTRODUCTION}

PERTEKMA (Persatuan Teknologi Maklumat) is a student association established and registered under the Centre of Students Development UNIMAS on 1st November 1997. The objective of PERTEKMA is to build an intermediate platform for proactive and effective interaction and communication between the faculty and its students. To finance student activities, PERTEKMA has several sources of income to keep the association running smoothly. One of the primary sources of income for PERTEKMA is from the food kiosk. The kiosk earns revenues by selling various food and beverages for the university staff and students on weekdays. Excos from PERTEKMA are appointed to manage the kiosk by selling products obtained from suppliers, collecting revenues earned from daily sales at the kiosk, and preparing a financial report for the kiosk revenue. Another source of revenue for PERTEKMA is payment collected from faculty events that generate income, such as FCSIT Annual Dinner, sports events, and contributions from other organizations. Account-related information is stored in an Excel spreadsheet system maintained by different Exco members. A problem arising from this system is the difficulty of searching of financial data entering and exiting the system.

This project developed a web-based system that keeps track of the PERTEKMA association's spending and revenue and prevents inconsistencies between different ledgers such as activity and kiosk ledgers maintained by various Exco members in PERTEKMA. The system would also be used as a financial reporting tool for PERTEKMA to better manage their flow of revenue and spending within a centralized platform. The financial reporting tool can only be accessible by authorized PERTEKMA Excos and supervisors. The system will allow users to carry out different tasks, including finding discrepancies between other ledgers maintained by different Exco members and balancing the ledgers depending on their user role. In addition, users will utilize the financial reporting website to record spending and revenue earned for every financial transaction that involves PERTEKMA. 


\section{PROBLEM STATEMENT}

A financial reporting tool is essential for an association to manage its cash flow and keep track of the spending on various events. Some benefits of a financial reporting tool include the improved accessibility of information, the ability to provide data interactively and the ability to provide specific information to the user based on their needs and in a timely manner (Fisher et al., 1999; Dolinšek \& Lutar-Skerbinjek, 1999). The use of the internet in financial reporting is on the increase among firms in the world (Mokhtar-E. S, 2017).

A sound financial management system reduces the hassle of keeping track of the expenditure while ensuring that the account is balanced. Such a system also ensures that the account can be audited and money spent by the organization can be accounted for. However, currently, PERTEKMA lacks a dedicated system to keep track of the association's spending, as every event has a separate spreadsheet to log its financial record. The way the data is being entered into the file in the spreadsheets is inconsistent. As a result, there are a lot of duplicated attributes, which is, unfortunately, one of the downsides of recording financial data manually. As the financial data grows, auditing the financial record increases in complexity due to spreadsheet data inconsistency, as the activity and kiosk ledges are separated and managed by different Excos. All monthly or quarterly reports have to be manually prepared and calculated. Therefore, there is a need for a mechanism that highlights problems found in the ledger caused by external factors. In response to this problem, this project proposed a financial reporting tool for PERTEKMA to manage its resources on a centralized platform, thus simplifying logging financial records and balancing accounts of different ledgers, namely the activity and kiosk ledgers.

\section{OBJECTIVES}

In this paper, we proposed the PERTEKMA Financial Reporting Tool that allows a centralized platform to enter financial data with supporting tools to analyze and visualize the financial data. The system's requirements were obtained through interview sessions and question and answers via Google form with the PERTEKMA Exco and advisors. The system can keep track of the PERTEKMA association's revenue and spending. It prevents inconsistencies between ledgers maintained by different parties such as the activity ledger, kiosk ledger, and advisors' ledgers. In order to view the summarize the data, the system would be able to periodically generate detailed financial reports.

\section{MATERIALS \& METHODS}

The system was developed based on the software development life cycle using Rapid Application Development (RAD) methodology. The following Table 1 show the four main phases, each phase's activities, and the activities performed based on the methodology. 
Table 1: The six phases and activities of RAD (Singh, 2020)

\begin{tabular}{|c|c|}
\hline Phases & Activities \\
\hline Analysis and Quick Design & $\begin{array}{l}\text { a) Interview and Q\&A session with PERTEKMA } \\
\text { authorities. } \\
\text { b) Define functional requirement } \\
\text { c) Logical Design } \\
\text { - Use Case Diagram } \\
\text { - Sequence Diagram } \\
\text { - Activity Diagram } \\
\text { d) Plass Diagram } \\
\text { - Graphical User Interface Design }\end{array}$ \\
\hline Build & $\begin{array}{l}\text { a) Front-end website development } \\
\text { b) Back-end website development }\end{array}$ \\
\hline Demonstrate & $\begin{array}{l}\text { a) Demonstrate the prototype to the supervisor and user } \\
\text { b) Gather feedback and comments from supervisor and user } \\
\text { c) Record and analysis any change in requirements }\end{array}$ \\
\hline Refine & $\begin{array}{l}\text { a) Refine the prototype based on the feedback and comments } \\
\text { b) Rebuild the prototype } \\
\text { c) Repeat phases two and three until all requirements are met }\end{array}$ \\
\hline Testing & $\begin{array}{l}\text { a) Perform overall testing on the final prototype } \\
\text { b) Record the testing results }\end{array}$ \\
\hline Implementation & Implement the proposed system \\
\hline
\end{tabular}

\section{Requirement Analysis}

Requirement Analysis is performed in the analysis and quick design phase of RAD; several parts will be covered, such as interview sessions with stakeholders, listing of functional requirements, logical and physical design. First, an interview session is carried out with PERTEKMA's treasurers to determine the feasibility of the proposed system. Second, a question and answer session is also carried out with PERTEKMA's advisors to gather their requirements to determine the scope of the system. Functional requirements include the main functions of the system. The logical design consists of use case diagram, sequence diagram, activity diagram and class diagram. The physical design consists of the graphical user interface design of the proposed system.

Functional requirements were created to provide an overview of requirements of every stakeholder involved in this project. Six types of users were identified for this proposed system: super administrator, PERTEKMA Advisor, PERTEKMA Treasurer, PERTEKMA Exco Supplier, PERTEKMA Exco Staff, Entrepreneurship Representative FSKTM and Faculty Dean. In this design, all the users are focused on managing and keeping track of PERTEKMA's financials. Table 2 details the functional requirements identified from the discussion with PERTEKMA's treasurer. 
Table 2: Functional Requirements

\begin{tabular}{|c|c|c|}
\hline & User: PERTEKMA Treasurer & \\
\hline FR.PT01 & Login to the proposed system. & High \\
\hline FR.PT02 & $\begin{array}{l}\text { View dashboard in the proposed system which is including view the } \\
\text { balance, revenue and expense in visualisation. }\end{array}$ & Medium \\
\hline FR.PT03 & $\begin{array}{l}\text { Manage revenue in the proposed system, which is including search, } \\
\text { add, delete, edit, view, export and import revenue details. }\end{array}$ & Medium \\
\hline FR.PT04 & $\begin{array}{l}\text { Manage expense in the proposed system, which is including search, } \\
\text { add, delete, edit, view, export and import expense details. }\end{array}$ & Medium \\
\hline FR.PT05 & $\begin{array}{l}\text { Manage event financial in the proposed system which is including } \\
\text { search, add, delete, edit, view and print event details. }\end{array}$ & Medium \\
\hline FR.PT06 & $\begin{array}{l}\text { Manage change log in the proposed system which is including } \\
\text { resolve and view log details. }\end{array}$ & Medium \\
\hline FR.PT07 & $\begin{array}{l}\text { Generate report in the proposed system which is including filter } \\
\text { report details, export and print report. }\end{array}$ & Medium \\
\hline
\end{tabular}

\section{Use Case Design}

Figure 1 is a use case diagram of this system. There are 6 actors that represent users of the system which are the Super Administrator, PERTEKMA treasurer, PERTEKMA Exco that is in charge of suppliers, PERTEKMA Exco that is in charge of managing kiosk staff, PERTEKMA advisor, Entrepreneurship Representative FSKTM and the Faculty Dean. The use case diagram consists of eleven use cases. Each use case will have a description that describes how the task is performed through the system. Due to the complexity of recording financial data workflow and the many stakeholders involved, an activity diagram was designed to aid understanding and to validate the requirements. The activity diagram describes the workflow of the system and the flow of messages from one activity to another. 


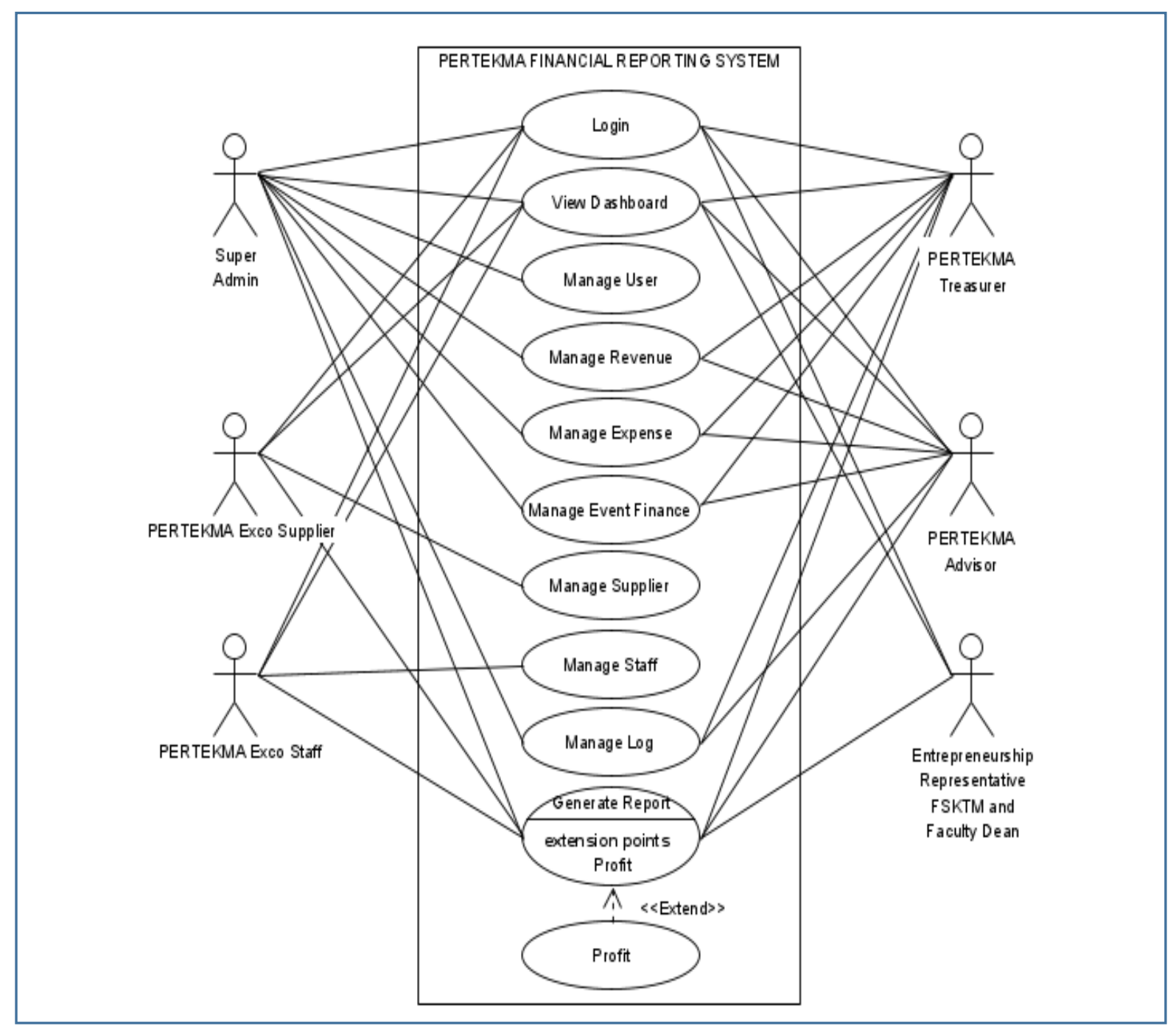

Figure 1: Use Case Diagram

\section{Activity Diagram}

Figure 2 shows an activity diagram for a user to manage suppliers. At the start of the activity, the system will display the supplier page to the user. The supplier page consists of a list of all suppliers. Next, users can select an action such as adding a new supplier, viewing the supplier's detail, searching the supplier, editing the supplier, altering the supplier, and exporting the supplier list. After completing the action, the activity is ended. 


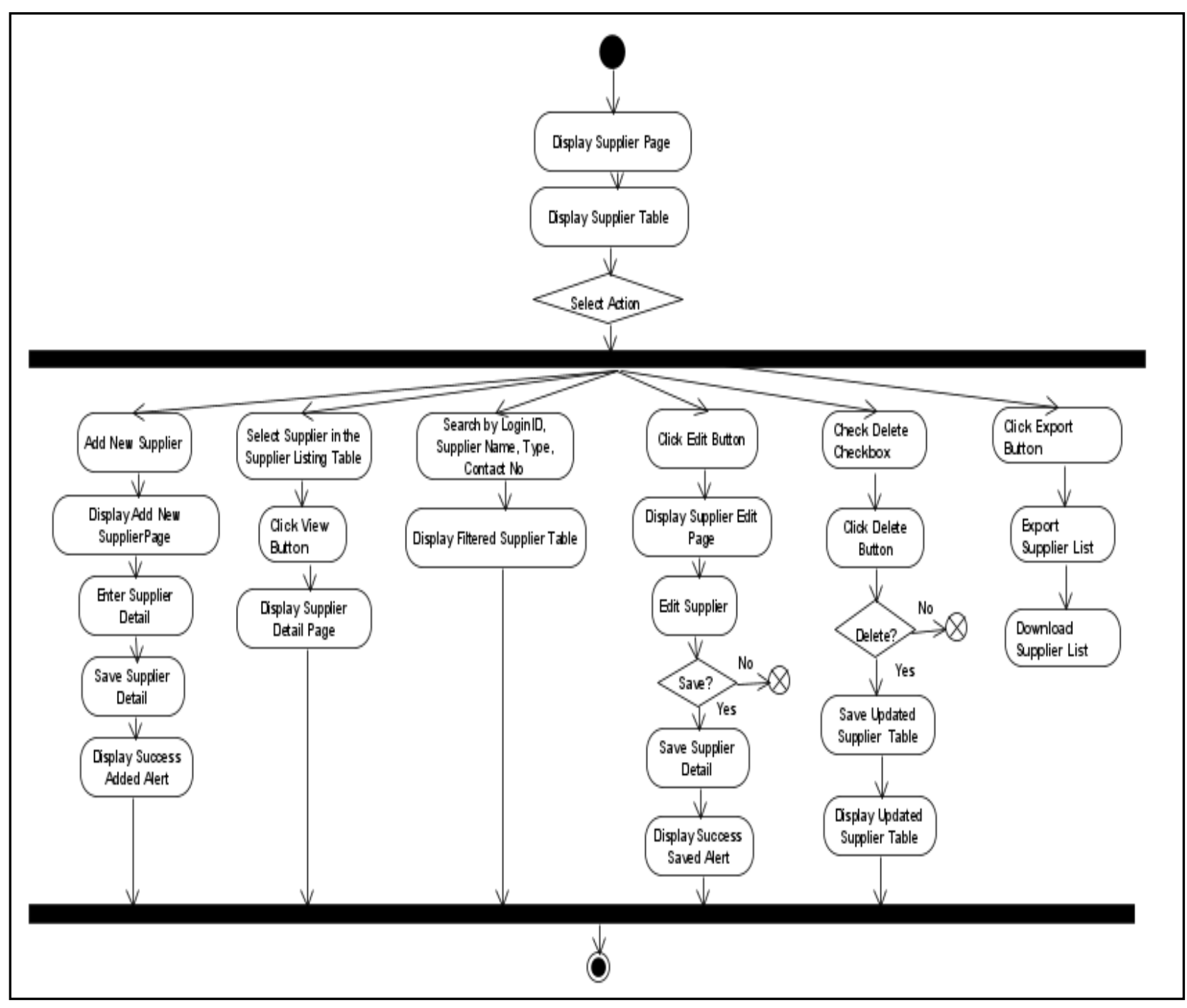

Figure 2: Activity Diagram for Manage Supplier

\section{Physical Design}

Figure 3 shows the users' graphical user interface design to view the dashboard. Users can view the revenue amount, expense amount, balance amount, and graph representation of the sale performance on the dashboard page. In addition, the dropdown box allows the user to choose the graph representation for the current year or any year before that. 


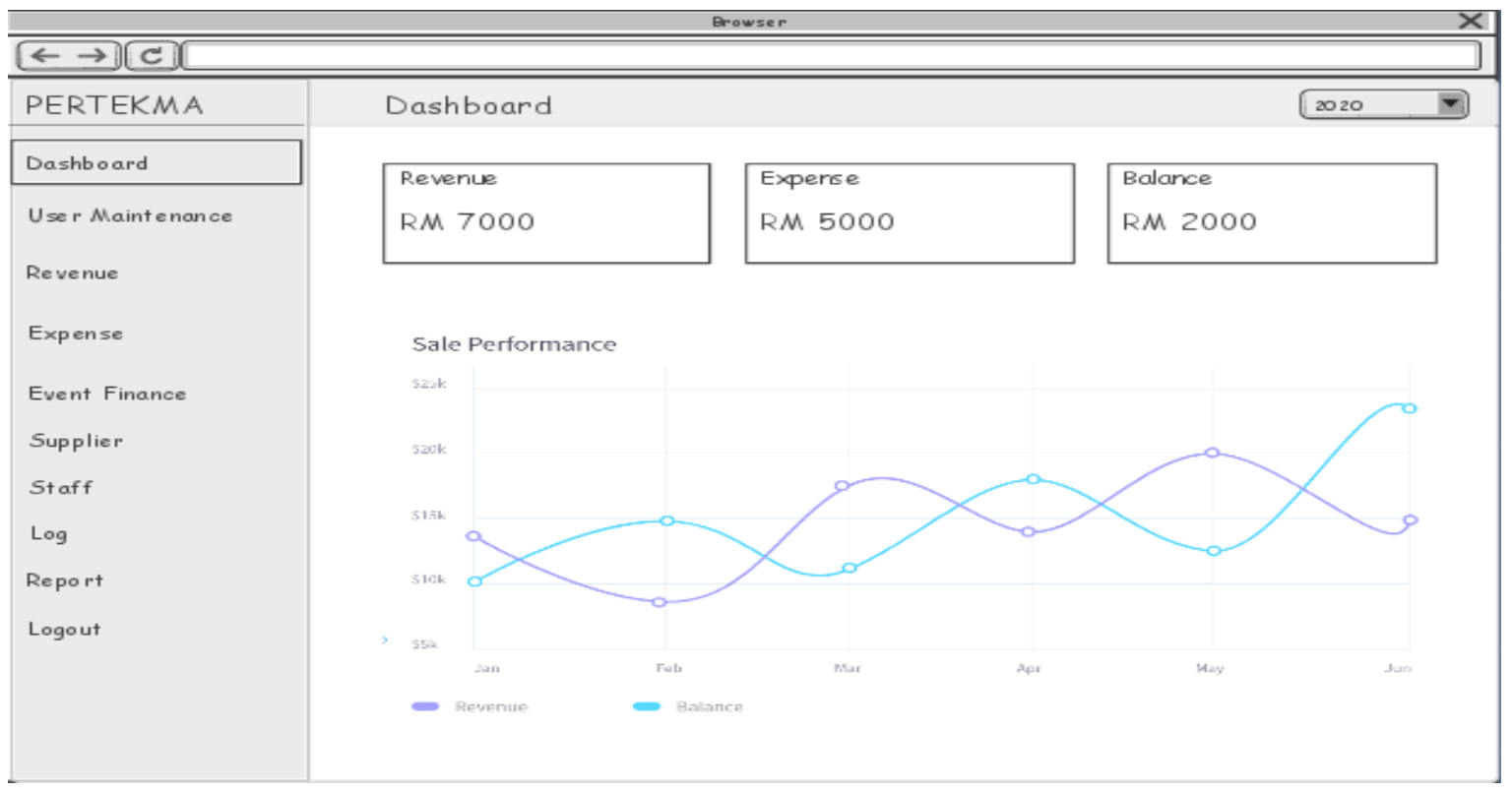

Figure 3: Graphical User Interface Design for Dashboard

Figure 4 shows the graphical user interface design for users to manage revenue. Users can perform add, search, view, delete, edit, and export the revenue details on the revenue page.

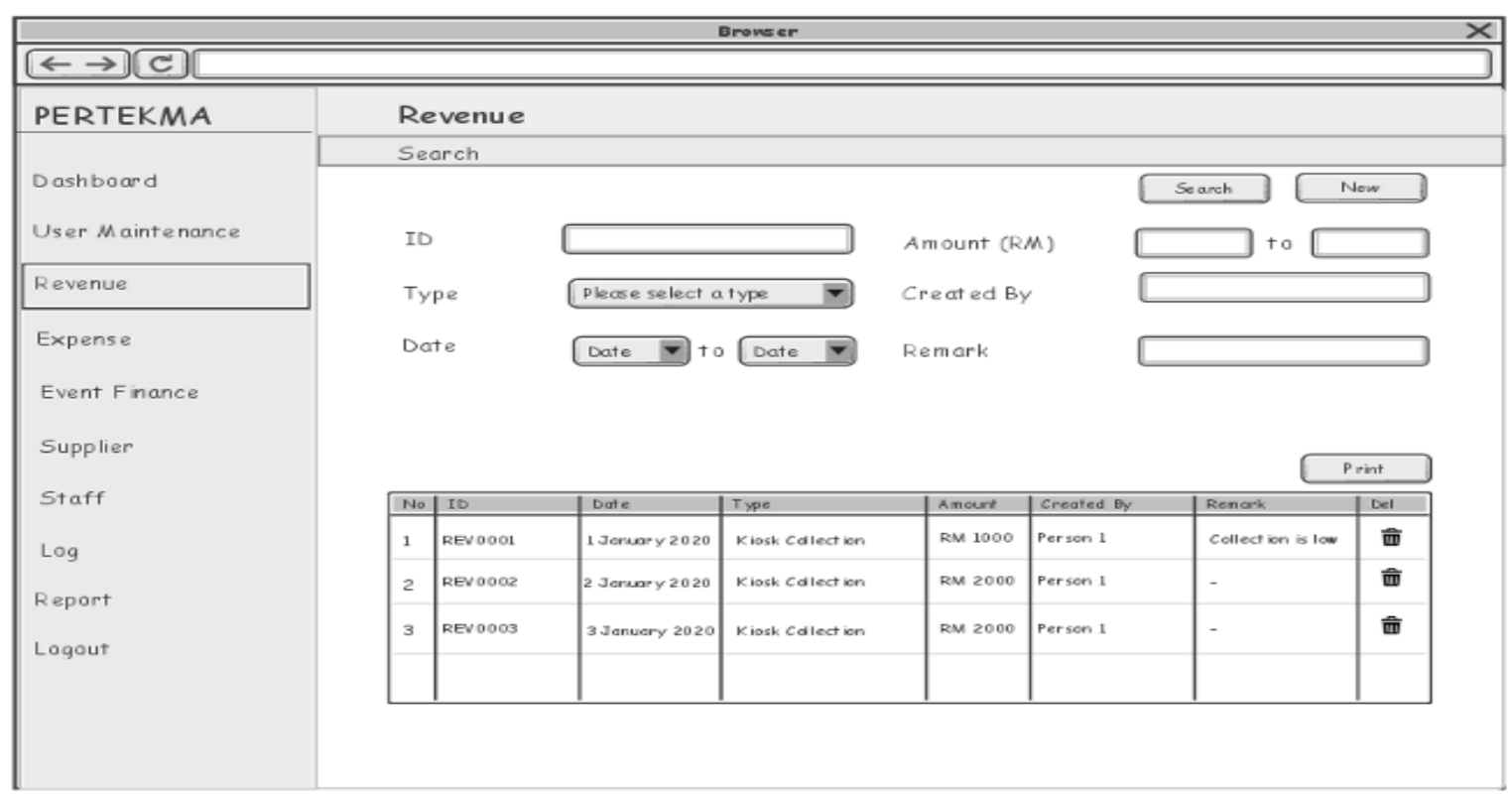

Figure 4: Graphical User Interface Design for Revenue 


\section{Implementation}

The system was developed using Visual Studio 2019 as the primary IDE of the project. Microsoft Visual Studio 2019 is chosen as it offers a wide variety of extensions and template for ASP.NET development. Microsoft Visual Studio also provides a simple and clear user interface and guide to connect the project to Microsoft Azure, which is the project's server. ASP.NET will be the primary programming language used to develop the system, and SQL Server 2014 Management Studio is used as the project's database. MSSQL provides an easy integration alongside with Microsoft Visual Studio and Microsoft Azure. To deploy MSSQL database tables to Microsoft Azure SQL, the user would only have to export the database into a ".bacpac" file and import it using Microsoft Azure graphical user interface. Finally Microsoft Azure is chosen as the primary server to host the website, database, and images.

\section{RESULTS \& DISCUSSION}

\section{Interface}

\section{A. Dashboard}

Figure 5 shows the dashboard page presented to the user after logging in. The dashboard page shows the yearly or monthly revenue sales chart. In addition, the dashboard page displays the total revenue, total expense, and total balance for the year. The bar graph shows the year's monthly revenue, expense, and profit. Yearly data can be viewed by selecting the year using the dropdown box on the top right corner of the page.

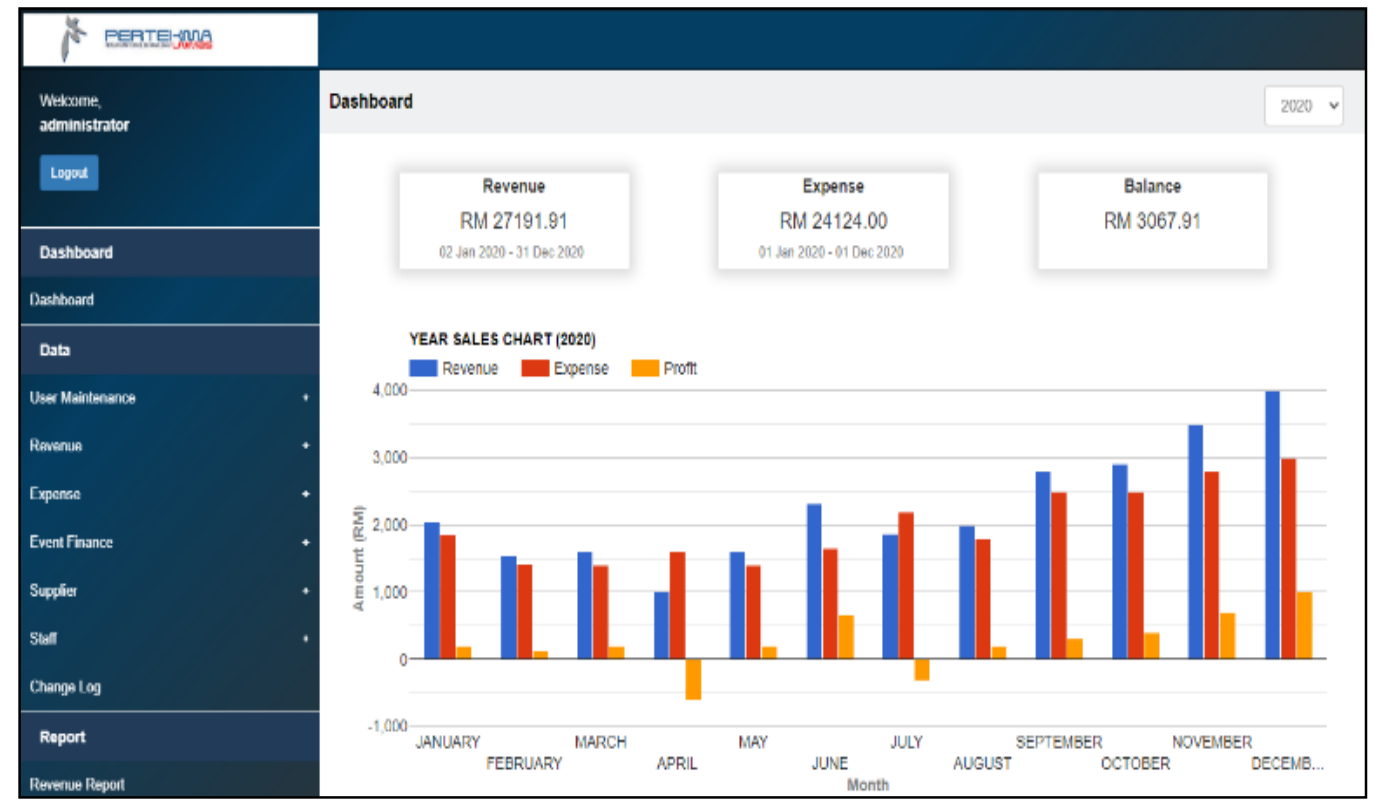

Figure 5: Dashboard Page

B. Add New Revenue

Figure 6 is the new revenue page. This page automatically generates a revenue ID and allows the user to store the type, date, and amount of the revenue to enter a remark. In addition, users can add revenue by using an already provided CSV template. 


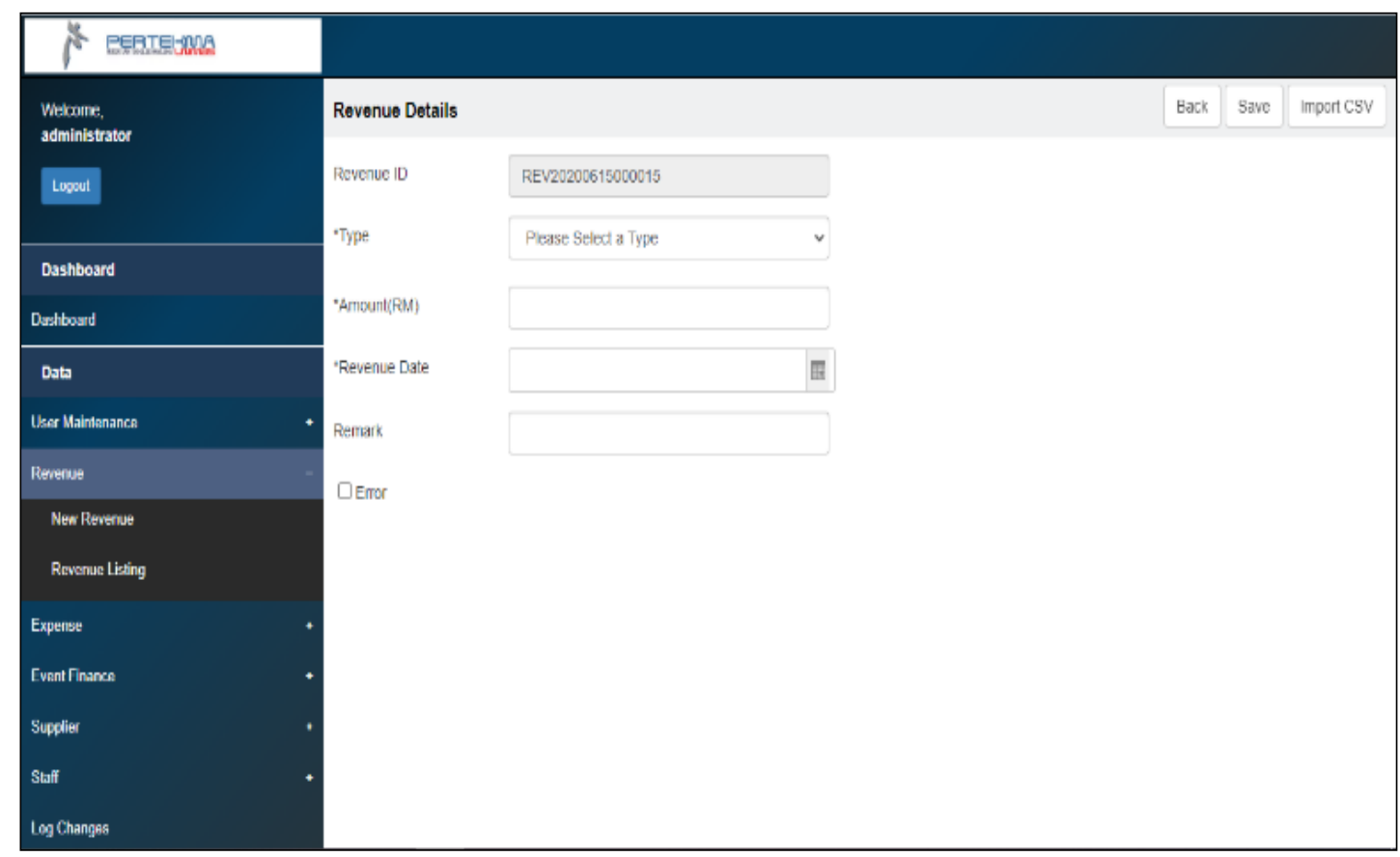

Figure 6: Add New Revenue

C. Revenue Listing

Figure 7 lists out the revenue that is saved by the user. The list can be filtered only to display revenue based on a range of dates. If there is a mistake, a user can delete the revenue on that particular date.

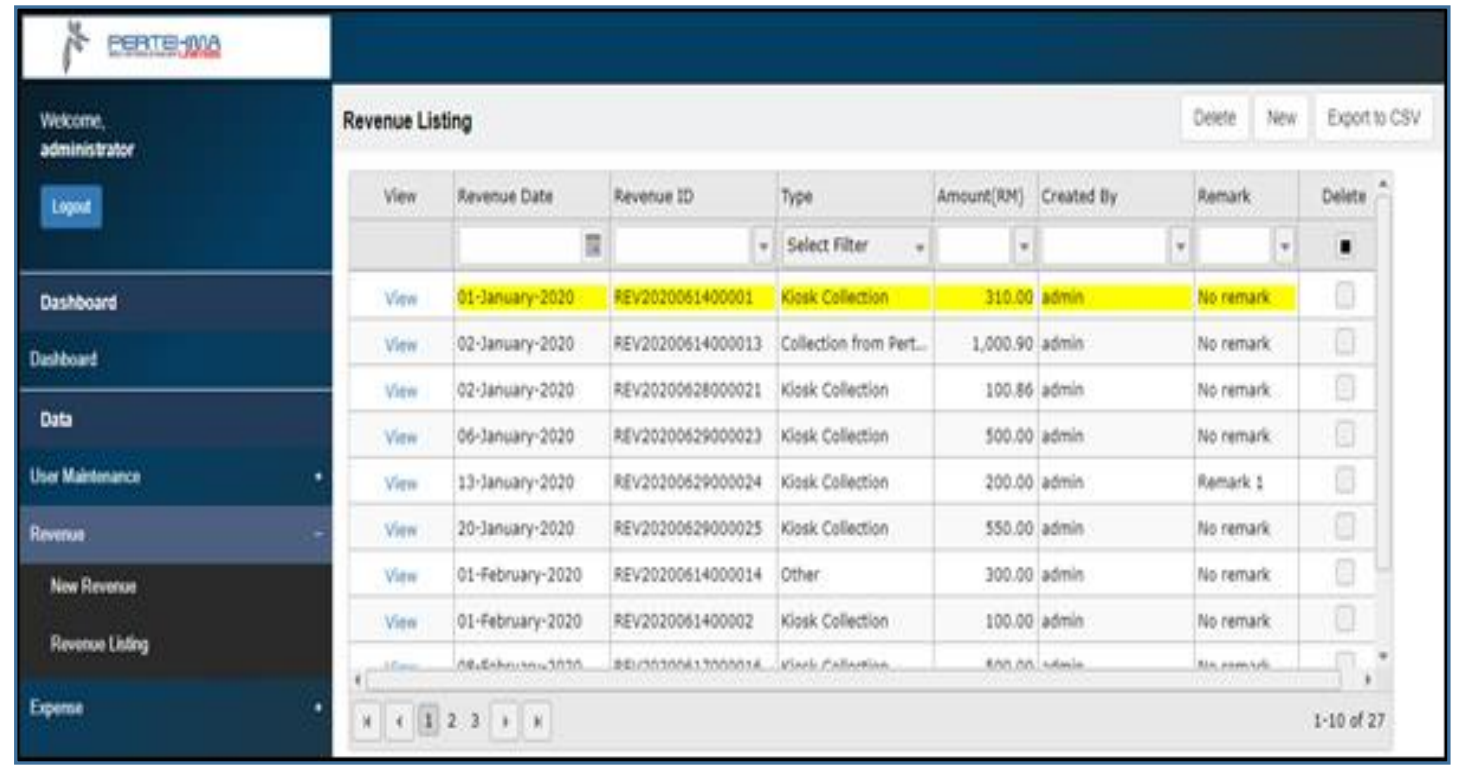

Figure 7: Revenue Listing Page

D. Generate Revenue Report

Figure 8 is the revenue report page where a user can select the report type, which is either a Daily Report, Monthly Report, or Yearly Report. The user also can filter the report by revenue type, range of amount, and content of revenue date. Finally, the Generate button will generate a report based on the options selected. Figure 9 shows the daily revenue viewer report page. 


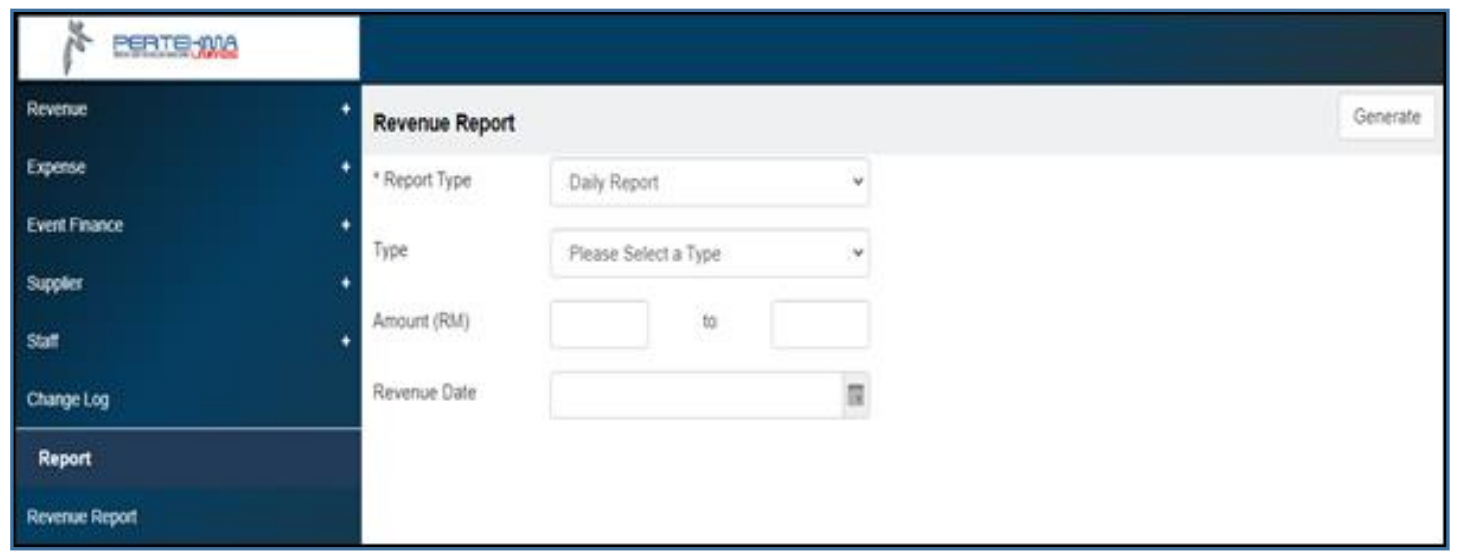

Figure 8: Revenue Report Query Page

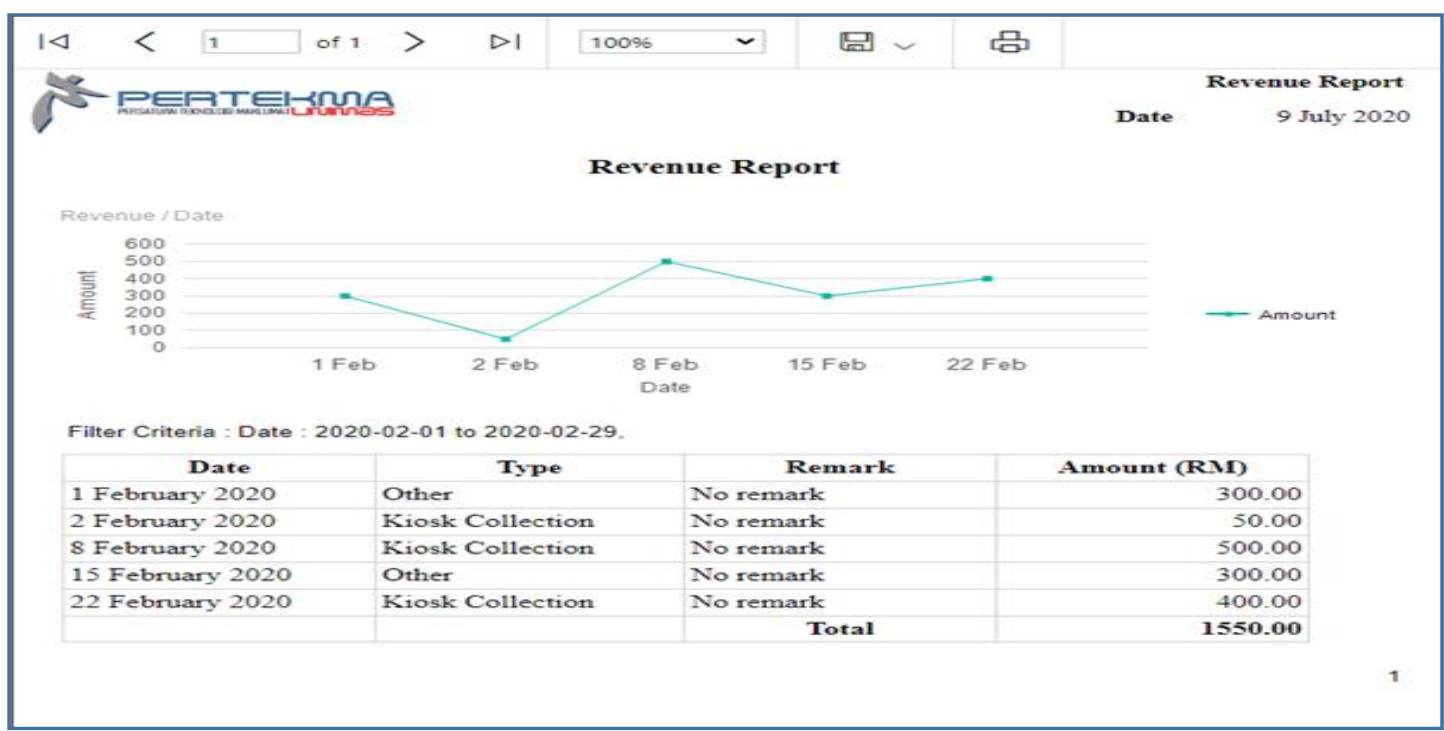

Figure 9: Daily Revenue Viewer Report Page

E. Generate Monthly Report

Figure 10 shows the monthly report page. The monthly report page is designed based on the format requested by the university. The system generates the report in PDF format and can be downloaded into a device or printed out. 


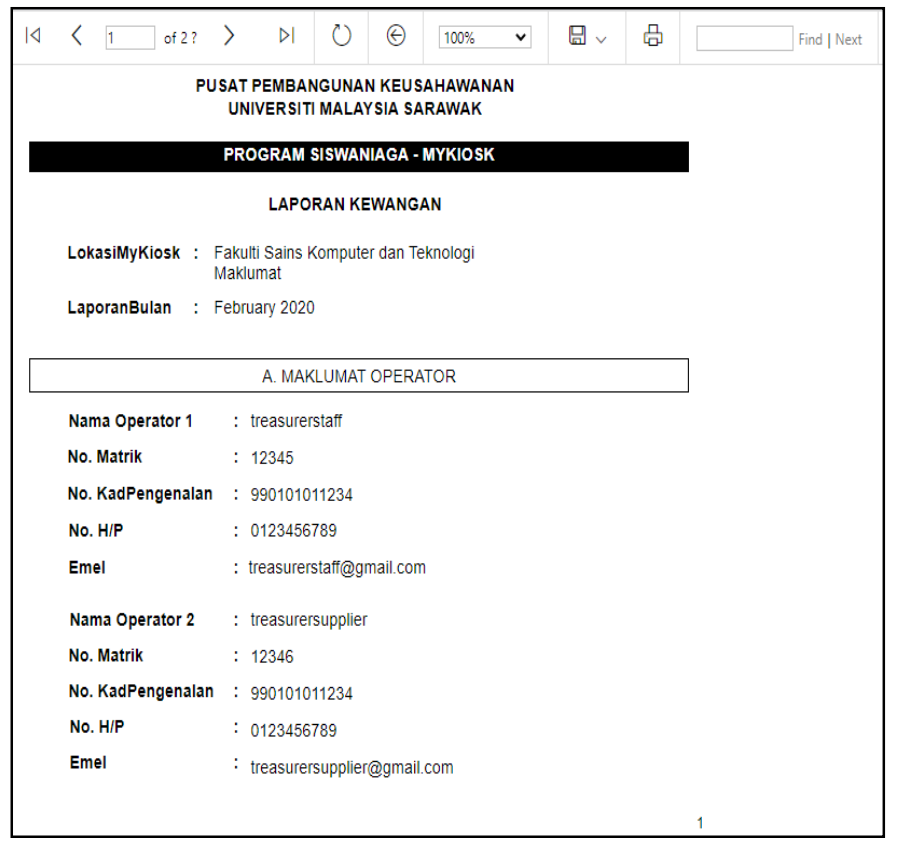

Figure 10: PERTEKMA Monthly Report

Functionality testing and user testing were carried out; the user provided feedback and suggestions from their usage of the system, which were taken into account to further improve the system. The user testing is done by appropriate users who are 1) 2 PERTEKMA advisors, 2) 2 PERTEKMA Treasurer, and the faculty student affairs deputy dean. The user testing method applied is by testing the system in the real world, after which users were required to answer a few survey questions as displayed in Figure 11. In summary, all users agreed that the functionality provided met their requirements and the user interface design was well understood.

Section A: Questions regarding functionality of the PERTEKMA Financial Reporting Tools.

\begin{tabular}{|l|l|l|l|l|}
\hline No. & Questions & Yes & No & Comments \\
\hline 1. & $\begin{array}{l}\text { I can login as an advisor with the usemame } \\
\text { "advisor" and password "advisors123". }\end{array}$ & & & \\
\hline 2. & I able to view dashboard page. & & & \\
\hline 3. & I able to add new revenue. & & & \\
\hline 4. & I able to review revenue details. & & & \\
\hline 5. & I able to update revenue details. & & & \\
\hline
\end{tabular}

Figure 11: Survey questionnaire for advisor

\section{CONCLUSION}

In conclusion, the project has met its objectives. The PERTEKMA Financial Reporting Tool allows PERTEKMA Excos to manage their finances on a centralized platform. Financial data are categorized and labelled by date, and financial graphs can be automatically generated for ease of understanding. In addition, the laborious and errorprone method of preparing monthly data reports has been automated, where reports are automatically generated based on the user criteria selected by the user.

In order to further improve the system, some of the following improvements could be made:

a. The system can be extended to support file formats other than CSV format.

b. The system could also be implemented into a mobile version where data can be entered and displayed using mobile devices. 


\section{REFERENCES}

Dolinšek, T., \& Lutar-Skerbinjek, A. (2018). Voluntary disclosure of financial information on the internet by large companies in Slovenia. Kybernetes. The International Journal of Cybernetics, Systems and Management Sciences, 47(3), 458-473.

Fisher, R., Laswad, F., \& Oyelere, P. (1999). Online Electronic Financial Reporting: Practices and Issues, Commerce Division Discussion Paper No. 76, Lincoln University.

Mokhtar, E.S. (2017). Internet financial reporting determinants: a meta-analytic review. Journal of Financial Reporting and Accounting, 15(1), 116-154. https://doi.org/10.1108/JFRA-07-2016-0061

Singh, V. (2020, December 10). What is Rapid Application Development Model (RAD)? https://hackr.io/blog/rapid-application-development-model 